\section{Summary}

Three cases of multiple sclerosis are reported, all of which developed chorea, choreo-athetosis, or athetosis during the course of their illness. The diagnoses were based on the association of diffuse and disseminated neurological lesions, a history of remission and relapse, a strongly paretic Lange curve in the C.S.F. with a negative Wassermann reaction, together with marked increase in the gammaglobulin fraction. Two cases responded well to corticotrophin and one improved spontaneously. Follow-up showed satisfactory remission of the whole clinical picture and of voluntary movements in particular.
I am grateful to Dr. J. MacDonald Holmes for permission to report his cases. I am indebted to Dr. E. R. Bickerstaff for permission to publish the case under his care and for his criticism and guidance in preparing this paper. I am thankful to Miss G. M. Griffiths and Miss S. Ray for their help at various stages.

\section{REFERENCES}

Balestrieri, A. (1955). G. psichiat. Neuropat., 83, 597.

Lance, J. W. (1963). 7. Neurol. Neurosurg. Psychiat., 26, 51. Matthews, W. B. (1958). Brain, 81, 193.

Mouren, P., Tatossian, A., Toga, M., Poinso, Y., and Blumen, G. (1966), Encéphale, 55, 212

\title{
Verapamil in Angina: a Double-blind Trial
}

\author{
D. N. PHEAR,* M.A., M.D., M.R.C.P., M.R.A.C.P.
}

Angina is a common and sometimes disabling symptom. So far, only two drugs of proved value are available for the symptomatic relief of angina. These are glyceryl trinitrate, effective but short-acting, and propranolol, which may precipitate heart failure by blocking the powerful $\beta$-adrenergic stimulation on which a damaged heart depends (Gillam and Prichard, 1965). Other effective drugs with prolonged action would be valuable, and verapamil has been reported to improve anginal pain. Verapamil is probably not a $\beta$-adrenergic blocking agent (Bateman, 1967), but has a non-specific depressant action on the myocardium (Fitzgerald and Barrett, 1967).

A double-blind trial of verapamil in 20 outpatients with angina is here reported.

\section{Method of Trial}

Twenty outpatients with angina took part in the trial ; there were 13 men and 7 women, with mean age of 58.1 years. All had troublesome angina requiring from 1 to 10 glyceryl trinitrate tablets daily (mean 3.7 tablets) for relief, even in a limited life. The electrocardiogram was normal in seven patients and showed a pattern of old myocardial infarction in four, with minor ischaemic changes in the remaining nine. Ten patients also had anticoagulant treatment with phenindione throughout the trial.

Each patient received verapamil $80 \mathrm{mg}$. three times daily for two weeks and identical control tablets for a further fortnight. The treatment periods were arranged by a double-blind randomized scheme, so that 10 patients started on verapamil and 10 on control tablets. Patients were seen fortnightly and assessed without knowing which tablets were being taken. The frequency and severity of angina were estimated, together with the number of glyceryl trinitrate tablets required and the amount of activity possible.

\section{Results}

Four patients preferred verapamil to the control tablets, and three preferred the control tablets to verapamil. Only two patients showed great improvement during the trial and became

* Consultant Physician, St. Albans City Hospital and Queen Elizabeth II Hospital, Welwyn Garden City. free of angina; one of these was taking verapamil and one control tablets. Nine patients noticed no change in angina throughout both trial periods, three were improved during both verapamil and control periods, and one patient was worse in both periods, having been on propranolol before the trial.

No side-effects were reported with either verapamil or the control tablets. The sensitivity to phenindione of the 10 patients on this drug did not alter significantly throughout the trial.

\section{Discussion}

The present study shows no evidence of useful relief of angina by verapamil. This drug has been introduced as a mild blocker of the $\beta$-adrenergic receptors in heart muscle (Bateman, 1967). Verapamil, however, does not prevent the tachycardia produced by isoprenaline in man, nor does it reduce tachycardia after exercise in healthy volunteers as propranolol does (Fitzgerald and Barrett, 1967) ; and verapamil probably acts as a non-specific myocardial depressant, like procainamide or quinidine. Animal experiments have shown that verapamil increases coronary blood flow (Haas, 1964), but a number of drugs with this action have not proved useful for relief of angina (Phear, 1963). The reason, no doubt, is that the coronary blood flow is increased by verapamil in healthy subjects but not in patients with coronary artery disease (Luebs et al., 1966).

Uncontrolled clinical trials have shown good results in some 1,400 patients with angina; Hoffmann (1964), for instance, reported satisfactory or excellent relief of angina in $90 \%$ of 191 patients. It is well known, however, that only doubleblind trials are acceptable, because of the natural fluctuations of angina and the frequent placebo effects recorded with new treatments for angina. Two previous double-blind trials have been reported. Atterhög and Porjé (1966) showed that the performance of 13 men during an exercise test on a bicycle ergometer was improved by verapamil; and Neumann and Luisada (1966) compared verapamil with placebo in 30 residents of an old people's home, and found that the consumption of glyceryl trinitrate from their weekly allocation was less while on verapamil than in the control period. These patients were elderly, average age 80.4 years, and inactive; also, the average number of anginal attacks was 8.8 per week, but the average 
reduction of glyceryl trinitrate intake on verapamil was 16.1 tablets a week, suggesting that glyceryl trinitrate was used rather arbitrarily and not only for angina. Neither trial corresponds to the ordinary conditions of ambulant treatment.

\section{Summary and Conclusions}

A double-blind trial is reported of verapamil in 20 outpatients with angina. The dose of verapamil was $80 \mathrm{mg}$. three times daily for a fortnight, with a similar period on placebo tablets. No significant relief of angina by verapamil was found.
I am grateful to Dr. F. J. A. Bateman, of Pfizer Ltd., for supplies of verapamil (Cordilox) and control tablets.

\section{REFERENCES}

Atterhög, J.-H., and Porjé, G. (1966). Svenska Läk.-Tidn., 63, 2071. Bateman, F. J.'A. (1967). Lancet, 2, 418. Fitzgerald, J. D., and Barrett, A. M. (1967). Lancet, 2, 310 Gillam, P. M. S., and Prichard, B. N. C. (1965). Brit. med. f., 2, 337 Haas, H. (1964). Arzneimittel-Forsch., 14, 461 Hoffmann, P. (1964). Med. Klin., 59, 1387.

Luebs, E.-D., Cohen, A., Zaleski, E. J., and Bing, R. J. (1966). Amer f. Cardiol., 17, 535 .

Neumann, M., and Luisada, A. A. (1966). Amer. 7. med. Sci., 251, 552 Phear, D. N. (1963). Brit. med. F., 1, 1608.

\section{Preliminary Communications}

\section{Hospital Study of Transferable Drug Resistance}

Brit. med. F., 1968, 2, 741-742

Transferable drug resistance in enteric pathogens was first discovered in Japan by Ochiai et al. (1959) and Akiba et al. (1960). It was subsequently reported in London (Datta, 1962). Since then enterobacteria with transferable resistance factors, or $\mathrm{R}$ factors, have been isolated in many parts of the world. The subject has been reviewed by Watanabe (1963, 1966), Datta (1965), and Anderson (1967).

There is more published information about the incidence of $\mathrm{R}$ factors in enteropathogenic bacteria than in normal flora. Multiresistant non-pathogenic Escherichia coli strains carrying $\mathrm{R}$ factors $(\mathrm{R}+)$ were isolated from a large number of patients in a Dublin children's hospital (Moorhouse, 1966). Resistance to two and three drugs was transferred to a sensitive $E$. coli $\mathrm{K} 12$ strain in mixed culture. These $\mathrm{R}+E$. coli strains were part of the intestinal flora of children who had been in hospital for some time. We did not know if the strains had been present in the intestinal tract of the children before admission or had been acquired in hospital. A small investigation was planned in an attempt to answer this question. The findings are the subject of this paper.

\section{Material AND Methods}

Twenty-two infants were selected for the investigation because they had faeces in their napkins on arrival at the hospital and had no recent history of diarrhoea. Faecal swabs were taken in the admission unit to ensure that the bacteria isolated were not acquired within the hospital. Faecal swabs were then obtained at intervals of one or two days until the infants were discharged from hospital.

Culture and Sensitivity Tests.-Each faecal swab was plated on a MacConkey agar plate for single colonies; it was also rubbed evenly over the whole surface of a second MacConkey plate to obtain a confluent bacterial lawn and a Multodisk (Oxoid $1141 \mathrm{E}$ ) was applied. The Multodisk contained the following drugs: ampicillin $25 \mu \mathrm{g}$., streptomycin $25 \mu \mathrm{g}$., tetracycline $50 \mu \mathrm{g}$., chloramphenicol $50 \mu \mathrm{g}$., and neomycin $30 \mu \mathrm{g}$. Any clearing around the discs was considered to indicate drug sensitivity. Lactose-fermenting colonies growing in the proximity of any of the discs were purified on a MacConkey agar plate and identified as $E$. coli from the following results: fermentation of lactose, glucose, maltose, and mannitol with the production of acid and gas; no fermentation of inositol; methyl-red positive; Voges-Proskauer negative ; indole positive ; and no growth in Koser's citrate medium. Single colonies were then tested for antibiotic sensitivity with the same Multodisk. At least 10 colonies were tested for slide agglutination with enteropathogenic $E$. coli antisera.

Resistance Transfer.-The recipient organism used was a strain of $E$. coli $\mathrm{K} 12, \mathrm{E} .711 \mathrm{~F}^{-}$, that was resistant to nalidixic acid but sensitive to the five antibiotics which we tested. It is easily distinguished from other $E$. coli strains because it does not ferment lactose and requires histidine, tryptophan, and proline for growth. Overnight broth cultures from a single colony of the donor strain and the recipient E.711 strain were prepared. Donor culture $0.2 \mathrm{ml}$. was mixed with recipient culture $1.8 \mathrm{ml}$. and the mixed culture was incubated overnight. Next day the mixed culture was centrifuged and the whole deposit was streaked out on MacConkey agar plates, each containing $20 \mu \mathrm{g}$. of nalidixic acid per ml. plus one of the drugs to which the donor strain was resistant. The concentration of the other drug in each plate was $25 \mu \mathrm{g} . / \mathrm{ml}$. On the following day any non-lactose-fermenting colony on the plates was picked off and identified as E.711 by its inability to ferment lactose and its amino-acid dependence. The resistance acquired was confirmed by testing with the same Multodisk as was used for the screening sensitivity tests.

\section{RESULTS}

The majority of the swabs yielded an apparently pure growth of $E$. coli. The remainder yielded mixtures of $E$. coli and Proteus, of $E$. coli and Streptococcus faecalis, and of $E$. coli, Proteus, and Str. faecalis. None of the $E$. coli strains isolated were known enteropathogenic serotypes.

Sensitivity Tests on Admission Swabs. - The sensitivity tests on the 22 admission swabs showed that $15(68 \%)$ of the 22 infants excreted resistant $\mathrm{R}+E$. coli strains, and eight of these strains were resistant to all five antibiotics (see Table).

Resistance Patterns of E. coli Strains Isolated from Admission Swabs \begin{tabular}{l|l|l|l|l|lll}
\hline $\begin{array}{l}\text { Resistance pattern ... } \\
\text { No. with each pattern }\end{array}$ & A S T C N & A S T C & A S T N & A S S T & A T T C & S T \\
\hline
\end{tabular} $\mathrm{A}=$ Ampicillin. $\mathrm{C}=$ Chloramphenicol. $\mathrm{S}=$ Streptomycin. $\mathrm{N}=$ Neomycin $\stackrel{A}{\mathbf{A}}=$ Ampicillin.

Nine of the 22 infants were admitted from other hospitals; seven of these were excreting resistant $\mathrm{R}+E$. coli. The other 13 came direct from their own homes and eight of them were excreting resistant $\mathrm{R}+$ strains.

Sensitivity Tests on Hospital Swabs.-Eleven of the 15 infants with resistant $\mathrm{R}+$ strains on admission continued to excrete these strains while in hospital, though some were in 